\title{
Preseismic anomalies in soil-gas radon associated with 2016 M 6.6 Meinong earthquake, Southern Taiwan
}

\author{
Ching-Chou $\mathrm{Fu}^{1}$, Vivek Walia ${ }^{2, *}$, Tsanyao Frank Yang ${ }^{3, * *}$, Lou-Chuang Lee ${ }^{1}$, Tsung-Kwei Liu ${ }^{3}$, \\ Cheng-Hong Chen ${ }^{3}$, Arvind Kumar ${ }^{2}$, Shih-Jung Lin ${ }^{2}$, Tzu-Hua Lai ${ }^{4}$, and Kuo-Liang Wen ${ }^{2}$ \\ ${ }^{1}$ Institute of Earth Sciences, Academia Sinica, Taipei City, Taiwan \\ ${ }^{2}$ National Center for Research on Earthquake Engineering, National Applied Research Laboratories, Taipei City, Taiwan \\ ${ }^{3}$ Department of Geosciences, National Taiwan University, Taipei City, Taiwan \\ ${ }^{4}$ Central Geological Survey, MOEA, New Taipei City, Taiwan
}

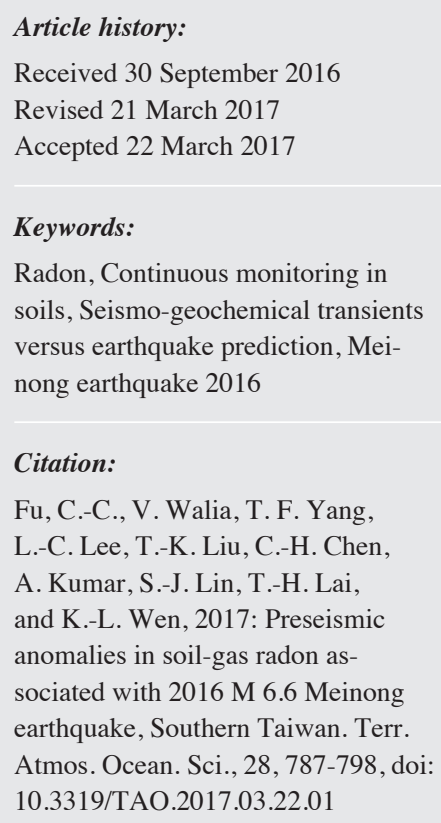

\begin{abstract}
Taiwan is tectonically situated in a terrain resulting from the oblique collision between the Philippine Sea plate and the continental margin of the Asiatic plate, with a continuous stress causing the density of strong-moderate earthquakes and regional active faults. The continuous time series of soil radon for earthquake studies have been recorded and some significant variations associated with strong earthquakes have been observed. Earthquake prediction is not still operative but these correlations should be added to the literature about seismo-geochemical transients associated to strong earthquakes. Rain-pore pressure related variations, crustal weakness at the studied faults system is consistent with the simultaneous radon anomalies observed. During the observations, a significant increase of soil radon concentrations was observed at Chunglun-T1 (CL-T1), Hsinhua (HH), Pingtung (PT), and Chihshan (CS) stations approximately two weeks before the Meinong earthquake $\left(\mathrm{M}_{\mathrm{L}}=6.6\right.$, 6 February 2016) in Southern Taiwan. The precursory changes in a multi-stations array may reflect the preparation stage of a large earthquake. Precursory signals are observed simultaneously and it can apply certain algorithms the approximate location and magnitude of the impending earthquake.
\end{abstract}

\section{INTRODUCTION}

The tectonic setting of Taiwan is such that it is considered to be one of the most seismically active regions in the world and is located at a convergent boundary between the Eurasian Plate and the Philippine Sea Plate. In the Southern part of the island the Eurasian Plate is subducting under the Philippine Sea Plate while in the Northern area of the island the Philippine Sea Plate bounded by the Ryukyu Trench, is subducting beneath the Eurasian Plate. Behind the Ryukyu Trench, the spreading Okinawa Trough has developed (Suppe 1984; Hu et al. 1996). The Northern part of the Taiwan Island is located at the Western extrapolation of the Okinawa Trough. Continuous collision between

\footnotetext{
* Corresponding author

E-mail:vivekwalia@rediffmail.com

** Deceased
}

Philippine Sea Plate and the Eurasian Plate has generated large and devastating earthquakes in the past. The number of earthquakes of magnitude 4 or above occur every year, both inland and offshore along the East coast of Taiwan and can be divided into two groups: (1) those associated with the Northward subduction and (2) those associated with active faults in Western Taiwan (Wu et al. 1999).

Recently a strong-moderate earthquake occurred on 6 February 2016, 03:57:26.1 (GMT 5 February 2016, 07:57:26.1), measuring $M_{L} 6.6$ on Richter scale, in Meinong district of Kaohsiung City, Taiwan and can be associated with earthquakes in the second category, occurring on active faults in Western Taiwan. According to Seismological Center of the Central Weather Bureau, the epicenter was located $22.92^{\circ} \mathrm{N}$ and $120.54^{\circ} \mathrm{E}(27.1 \mathrm{~km}$ Northeast from the Pingtung County) and had relatively shallow depth of $14.6 \mathrm{~km}$ 
(modified, earlier reported as a focal depth of $16.7 \mathrm{~km}$ ) with respect to the regional earthquakes (relatively shallow earthquakes). The earthquake was felt all over the island of Taiwan. The focal mechanism of this event has been reported by the Broadband Array in Taiwan for Seismology (BATS) and by the United States Geological Survey (USGS), both of which suggest a thrust mechanism with two nodal planes striking in the North-South (NS) and the Northwest-Southeast (NW-SE) directions (Wu et al. 2016).

During the last few decades, studies have shown useful data in the field of seismogeochemistry interpreted as geochemical precursory signals for impending earthquakes (Heinicke et al. 1992; Igarashi et al. 1995; Virk et al. 2001; Steinitz et al. 2003; Yang et al. 2005, 2006; Zmazek et al. 2005; Kumar et al. 2009, 2015; Walia et al. 2009a; Fu et al. 2015). Despite a full operative "earthquake prediction/early alarm" routine is still far to be accepted. Geochemical precursors are recognized as short-term precursor and are monitored in many countries both by discrete and continuous tools (Inan et al. 2008; Kuo et al. 2010), often preceded by area papers to install "sensitive stations" in sites recognized sound, during strong earthquakes in the past too, mostly if the role of fluids in triggering earthquakes is important (i.e., Italy, see Quattrocchi 1999). Radon is proved to be as one of the most reliable geochemical precursor (Wakita et al. 1980; Fleischer 1981; Igarashi and Wakita 1990; Heinicke et al. 1992; Igarashi et al. 1995; Virk et al. 2001; Steinitz et al. 2003; Yang et al. 2005; Zmazek et al. 2005; Kumar et al. 2009; Walia et al. 2009a; Fu et al. 2017a, b). Virk and Singh (1994) reported precursory radon anomalies simultaneously in both soil-gas and groundwater 5 days before the Uttarkashi Earthquake with a moment magnitude of 6.8 occurred on 20 October 1991, in Garhwal Himalayas, India. Walia et al. (2006) compiled radon time series interpreted as precursory signals for some major earthquakes having magnitude $>5$, which occurred in N-W Himalayas. Igarashi et al. (1995) interpreted precursory radon changes before the disastrous Kobe earthquake in Japan and this anomaly was particularly evident. Still more works should be dedicated to understand if certain delay between radon spikes and strong earthquakes is a time of preparation of those earthquakes, i.e., 40 up to 144 days before in a case history described by Einarsson et al. (2008) in the South Iceland seismic zone, whereas Jaishi et al. (2014) find a positive correlation between radon/thoron data and earthquakes soon after mainly, but sometimes are co-seismic. In Western Turkey the connection between radon and earthquakes was reported by Tarakci et al. (2014).

Our research is based on soil gas radon monitoring to find pre-seismic signals in the vicinity of different geological fault zones of Taiwan but more groundwater and multiparamertic stations may need to add in future to enhance the efficiency as suggested by some studies (Quattrocchi et al. 2000). To carry out the investigations, a network of continuous soil-gases monitoring stations in collaboration with National Center for Research on Earthquake Engineering (NCREE) and National Taiwan University (NTU) has been established along different faults (Fig. 1) to determine the possible correlation of radon concentrations anomalies in soil to monitor the tectonic activity in the region (Walia et al. 2009b; Yang et al. 2011). Based on the data generated at monitoring stations, we proposed a tectonic setting based

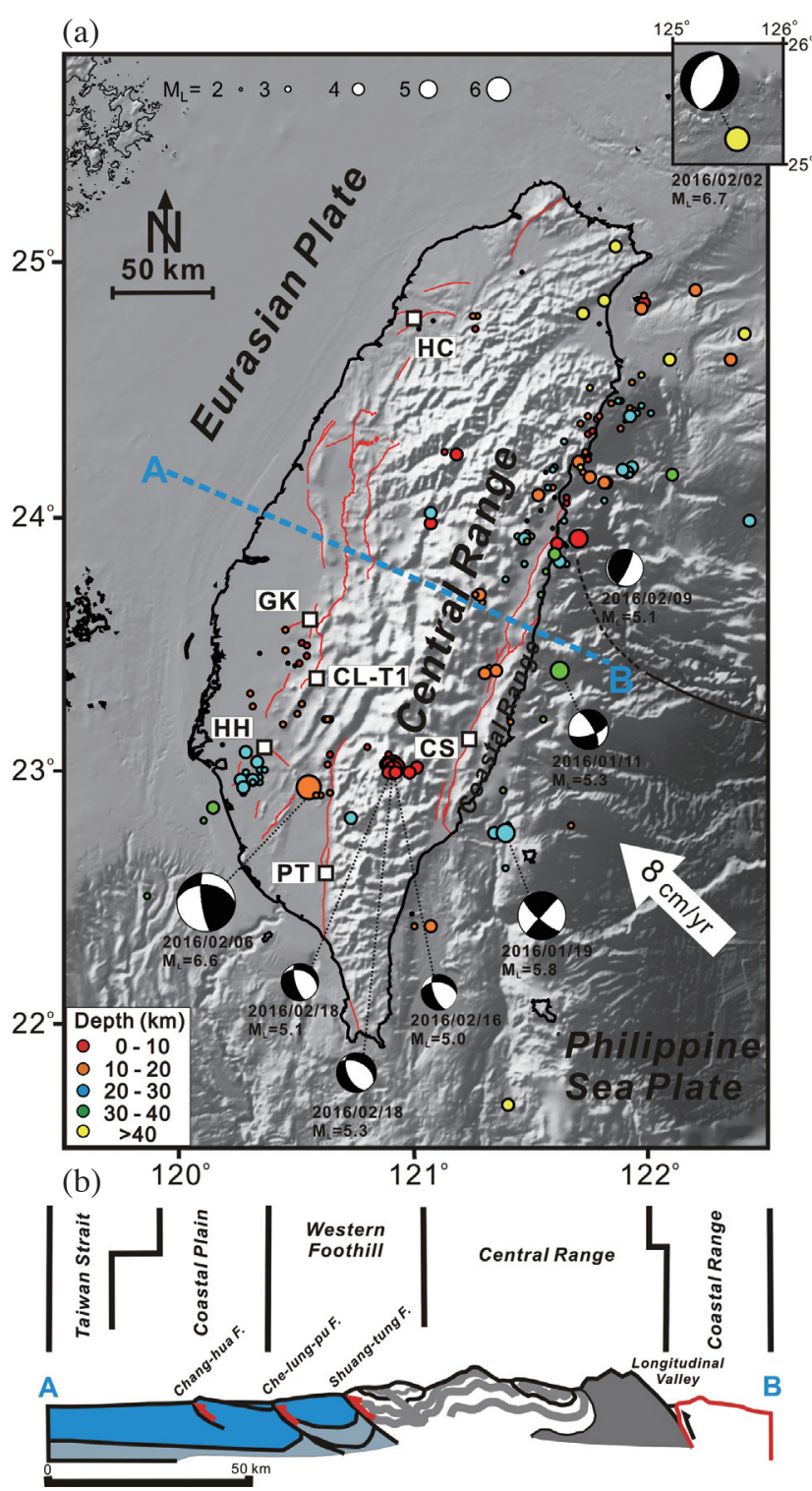

Fig. 1. (a) The simplified sketch of regional simplified map and principal tectonic lineaments/faults affecting around Taiwan shows the Philippine Sea plate moving toward Taiwan in a rate of $8 \mathrm{~cm} \mathrm{yr}^{-1}(\mathrm{Yu}$ et al. 1997). The red lines indicate the active fault proposed by the Central Geological Survey of Taiwan (Lin et al. 2000). The squares represent the location of the soil gas stations: HC: Hsinchu; CL-T1: ChunglunT1; HH: Hsinhua; PT: Pingtung; CS: Chihshang. The circle symbols represent the distributions of earthquake during the seismic sequences of 15 December 2015 to 15 March 2016. These are plotted in different colors with respect to their focal depth. (b) Geological profile along the A-B cross-section shown in (a). (Color online only) 
model and we tested the model during some big earthquakes happened in the past (Walia et al. 2013).

\section{METHODOLOGY}

To carry out the present investigation, temporal soilgases compositions variation was measured regularly together with earthquake monitoring stations, established along different faults (Fig. 1). Selected fault zones are categorized as active faults zones by Central Geological Survey of Taiwan and may be considered as conducive for earthquake precursory studies in Taiwan (e.g., Chyi et al. 2001, 2005, 2011; Fu et al. 2005, 2008, 2009, 2017a, b; Yang et al. 2005, 2011; Walia et al. 2009a, b, 2013). To build a monitoring station, reconstructions were done by digging holes of approximately $2.5 \mathrm{~m}$ and by casing these holes with PVC pipes. At the bottom of PVC pipe, a fine mesh is attached to avoid any unwanted materials to enter the pipe. The PVC sheet is put on all the sides of the PVC pipe at bottom covering about $1 \mathrm{~m}$ on all sides; this avoids the rainwater to get in the hole. Some pebbles are also put at the bottom to reduce the meteorological effects before filling the sides of the holes. Figure 2 shows the sketch of the established automated monitoring system. At the remote station after passing through the water trap and gas cooler, the soil gas was transferred into an alpha spectroscopy (SARAD RTM2100) via an internal pump for radon measurement (e.g., Hsinchu station, HC; Hsinhua station, HH; Chihshang, CS; Pingtung station, PT) (Fig. 1) (see Walia et al. 2009a). Simultaneous measurement of humidity and mathematical correction in the chamber was automatically calculated to obtain corrected radon concentrations in every $15 \mathrm{~min}$ integrated time. The monitoring stations were equipped with Strong Motion seismographs to find the local intensity of impending earthquake at monitoring station. All the data are downloaded remotely to the Taipei office for further analysis. As per the present practice, the data from all the stations are examined in real time to evaluate possible earthquake precursory signals as well as "false anomalies" against the backdrop of meteorological parameter which affect the time series of radon, as known from many papers (Pinault and Baubron 1996; Barnet et al. 1997; Gregorič et al. 2011; Pascale et al. 2015). Seismic parameters (viz. Earthquake parameters as recorded also at a monitoring station, etc.) and meteorological parameter data were obtained from Central Weather $\mathrm{Bu}-$ reau of Taiwan (http://www.cwb.gov.tw). The Chunglun-T1 (CL-T1) monitoring station is also used for the continuous recording of soil gas radon by a silicon photodiode solid state detector to compare the two methods. The electronics of the radon detection include the grounding of the circuit, the high voltage conversions, and counts registration process, which are housed into in a PVC pipe. The generation counting system is capable of recording radon flux changes other than concentration and concludes once every hour.
This methodology follows the same settings described in detail by Chyi et al. (2011).

The radon anomalies are usually recognized by using $+2 \sigma$ method, in which the anomaly thresholds are calculated with mean value and two standard deviation (Ghosh et al. 2007; Ramola et al. 2008; Oh and Kim 2015). In this study, we use a residual signal processing technique, in order to: (1) identify the anomalies in time series and (2) diminish the regular effects from environmental factors for data recorded. For our analysis, a residual signal of concentration dA can be determined as the difference between the observed signal intensity (soil radon concentration) and the average of several days preceding the observation day:

$\mathrm{dA}(\mathrm{t})=\mathrm{A}(\mathrm{t})-\mathrm{RA}(\mathrm{t})$

where, $A(t)$ is the trend of soil radon concentration at a time $\mathrm{t}$ for an observed day and RA(t) is the rolling average at the same time $t$ for -14 days (14 days before the observed day) the data recording is every $15 \mathrm{~min}$. The standard deviation of the residual results between the trend and rolling average of soil radon concentration can be determined. Then, an anomalous threshold value can be defined by using this kind of factor when it exceeds the identified standard deviation, and then can be used for the possible correlation with large seismic event, eventually associated to the highlighted anomalies.

Furthermore, the hourly precipitation records are available from a meteorological station as a whole, in the network, which is located at a distance of approximately $3 \mathrm{~km}$ from the monitoring station. All seismic data are taken from the earthquake catalogues of Central Weather Bureau (CWB). In total, there are 155 seismic events with local magnitudes $\left(\mathrm{M}_{\mathrm{L}}\right)$ ranging from $2.2-6.7$ during the monitoring period in

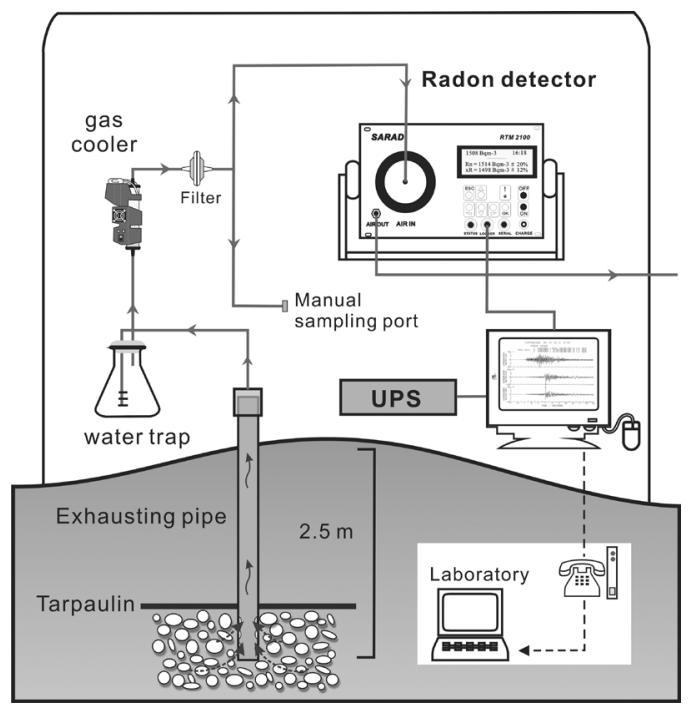

Fig. 2. The schematic sketch for continuous monitoring station. 
the Taiwan area. We report a table only for earthquake with $\mathrm{M}>5.0$ with the distance with respect the fulcrum of the monitoring network (Table 1).

\section{RESULTS AND DISCUSSIONS}

In the present study, we analyze and compare temporal patterns of radon concentration. Some anomalies are clearly associated with the Meinong earthquake and following aftershocks from the data recorded by the network of 5 discussed monitoring stations (Fig. 1). From the results of long term geochemical monitoring at the established monitoring stations we can divide the monitoring stations as belonged to two different tectonic zones (Walia et al. 2009b), i.e., North and South part of Taiwan, respectively. It has been found that variations in soil gas at North zone monitoring stations are disturbed with all probability more by the stress variation due to tectonic activities along Okinawa Trough and Ryukyu Trough, which are located in North and Central, Eastern part of Taiwan, respectively, in addition to local earthquakes (magnitude < 5) located within a radius of about $50 \mathrm{~km}$ from the monitoring station. On the other hand, in case of the South zone, soil-gas variations are more probably associated to tectonic activities along the Luzon Arc and other tectonic activities in the Southern part of Taiwan. Therefore, based on the recorded continuous time series, we infer that the monitoring stations, Southward, as a whole precursory signals of earthquakes occurring South - Southeastern part of Taiwan, whereas for the Northern zone stations, most of soil-gas anomalies, interpreted as precursory signals are recorded for the earthquakes that occurred in North or Northeastern part of Taiwan. These findings suggest to propose an interpretative model dividing Taiwan into two different tectonic zones, as part of these findings we reported in Walia et al. (2009b, 2013). Radon time series data are obtained from the discussed network of monitoring stations run by NCREE and NTU in collaboration and fit well in the proposed model. Based on the anomalous signals from the particular monitoring station we are near to identify the area for impending earthquakes of magnitude $\geq 5$ and we could test it for some earthquakes which occurred in the country during the last few years (Yang et al. 2011; Walia et al. 2013). Earthquakes having magnitude $\geq 5$ with recorded local intensity $\geq 2$ at the monitoring stations also reported by CWB (http://www.cwb. gov.tw), calculated epicentral distance $<100 \mathrm{~km}$ with focal depth $<40 \mathrm{~km}$ have shown precursory signals and fitted very well according to the proposed model.

It was observed that no precursory signals were found in Northern monitoring stations for the Meinong Earthquake (Fig. 3). Most of Southern monitoring stations located in South and Southeastern part of Taiwan, which had the local intensity $\geq 3$ for Meinong earthquake, have shown precursory signals (Figs. 4 - 7). The Southern-most station, i.e., PT monitoring station is located at about $31 \mathrm{~km}$ distance from the epicenter of Meinong earthquake and recorded local intensity of 5. Radon time series at PT station in the time window from 15 December 2015 to 15 March 2016 is shown in Fig. 4. From the previous years data it has been found that under normal condition radon values lie in between $15-20 \mathrm{kBq} \mathrm{m}^{-3}$ (Yang et al. 2011). Radon values started rising on 23 January 2016 approximately 14 days and approached maxima on 25 January 2016 (i.e., crossing $+2 \sigma$ level in standard deviation) about 12 days prior to Meinong earthquake, respectively. During the observation period of 12 January 2016 to 6 February 2016 there were more or a few anomalies crossing the standard deviation $+2 \sigma$. Although there was one major earthquake of magnitude 6.7 North of Keelung on 6 February 2016, however, this earthquake does not fit in the aforementioned selection criteria and was very far from the PT monitoring station. Otherwise, radon values started increasing on 13 January 2016 with maxima on 16 January 2016, and followed by one large earthquake with magnitude 5.8, which occurred on 19 January 2016 in Southeastern Taiwan. This event fit in the defined criteria and was at a distance of $86 \mathrm{~km}$ from the PT station. Co- and post-seismic slight changes can be observed during the period from 6 February to 18 February 2016, and these high concentration spikes may not be clearly related to pre-seismic events.

Radon monitoring for the earthquake precursory studies at the established $\mathrm{HH}$ monitoring station along the Hsinhua Fault in Tainan area has been done continuously since November 2006 (Walia et al. 2009b, 2013; Kumar et al. 2015). Radon time series in the time window from 15 December 2015 - 15 March 2016 at HH station is shown in Fig. 5. The HH monitoring station is located at about $26 \mathrm{kms}$ distance from the epicenter of Meinong earthquake and recorded local intensity of 5 . Radon started rising from 3 January 2016 after a hourly rainfall or accumulated daily rainfall was greater than 20 and $70 \mathrm{~mm}$, respectively at the station and nearby. This change was firstly attributed to big rainfall. But in turn, some literature reported the strict link between pore pressure increase (rain falls) and earthquake triggering (Sibson 1977; Quattrocchi 1999; Jimenez and Garcia-Fernandez 2000), however, in case of Taiwan it may not be applicable. For example, the excessive precipitation brought in by Typhoon Morakot in Southern Taiwan. The accumulated rainfall amounted to approximately $3000 \mathrm{~mm}$ from 7 - 10 August 2009, however, no large earthquakes occurred in Southern Taiwan after this extreme rainfall event. Therefore, the heavy rainfalls may not play a main role in the appearance of earthquake triggering in this study.

Any change in radon values at $\mathrm{HH}$ station due to big rainfall usually persists only for 7 - 10 days, however this rise in radon value did not return back to the threshold value (around $40 \mathrm{kBq} \mathrm{m}^{-3}$ ). Radon values almost reached $+2 \sigma$ in standard deviation on 6 January 2016. The noted radon increase is long term which usually not the case in previous 
data reported elsewhere Walia et al. (2013) and Kumar et al. (2015). The HH monitoring station is the nearest among the established stations to the epicenter of Meinong earthquake. Huang et al. (2016) proposed that faults at shallower depth under high fluid pressure and concentrated stress conditions can be triggered by a moderate lower crustal earthquake such as the Meinong earthquake. Such fluids have a higher pressure at the bottom part and then tend to migrate upwards through a crack system in the crust during the build-up of stress. It suggests that long term increase in radon values at HH monitoring station may be attributed to the stress building in the region before the Meinong earthquake. It can also be justified by the fact that CWB real-time strong ground motion station located in Hsinhua District, Tainan City had

Table 1. Catalog of related earthquakes $\left(M_{L} \geq 5\right)$ occurred from 15 December 2015 to 15 March 2016 in Taiwan.

\begin{tabular}{c|c|c|c|c|c|c|c|c|c|c|c}
\hline \multirow{2}{*}{ No. } & \multirow{2}{*}{ Date } & Long. & Lat. & Dep. & Mag. & HC & GK. & CL-T1 & CS & PT \\
\cline { 3 - 11 } & & $\left({ }^{\circ} \mathbf{E}\right)$ & $\left({ }^{\circ} \mathbf{N}\right)$ & $(\mathbf{k m})$ & $\left(\mathbf{M}_{\mathbf{L}}\right)$ & \multicolumn{5}{|c}{$(\mathbf{k m})^{\mathbf{1}}$} \\
\hline $\mathrm{a}^{2}$ & $2015 / 12 / 3108: 53$ & 121.8 & 21.41 & 147.4 & 5.0 & 382 & 273 & 253 & 199 & 185 \\
$\mathrm{~b}$ & $2016 / 01 / 1112: 52$ & 121.53 & 23.43 & 33.2 & 5.3 & 156 & 98 & 90 & 45 & 129 \\
$\mathrm{c}$ & $2016 / 01 / 1910: 13$ & 121.31 & 22.79 & 29.7 & 5.8 & 222 & 116 & 101 & 38 & 75 \\
$\mathrm{~d}$ & $2016 / 02 / 02 ~ 22: 19$ & 123.54 & 25.42 & 203.7 & 6.7 & 263 & 362 & 377 & 346 & 429 \\
$\mathrm{e}$ & $2016 / 02 / 06 ~ 03: 57$ & 120.54 & 22.92 & 14.6 & 6.6 & 212 & 75 & 51 & 75 & 31 \\
$\mathrm{f}$ & $2016 / 02 / 0908: 47$ & 121.69 & 23.89 & 5.7 & 5.1 & 119 & 118 & 128 & 97 & 178 \\
$\mathrm{~g}$ & $2016 / 02 / 1612: 04$ & 120.87 & 23.01 & 5.0 & 5.0 & 196 & 71 & 52 & 40 & 49 \\
$\mathrm{~h}$ & $2016 / 02 / 1809: 09$ & 120.87 & 23.02 & 5.4 & 5.3 & 195 & 70 & 51 & 39 & 50 \\
$\mathrm{i}$ & $2016 / 02 / 1809: 18$ & 120.88 & 23.03 & 4.3 & 5.1 & 194 & 69 & 51 & 38 & 51 \\
\hline
\end{tabular}

Note: 1: The distance between the epicenter of earthquake and monitoring station.

2: The earthquake is not plotted in Figs. 1 and 8, because the location of earthquake is outside of the figure.

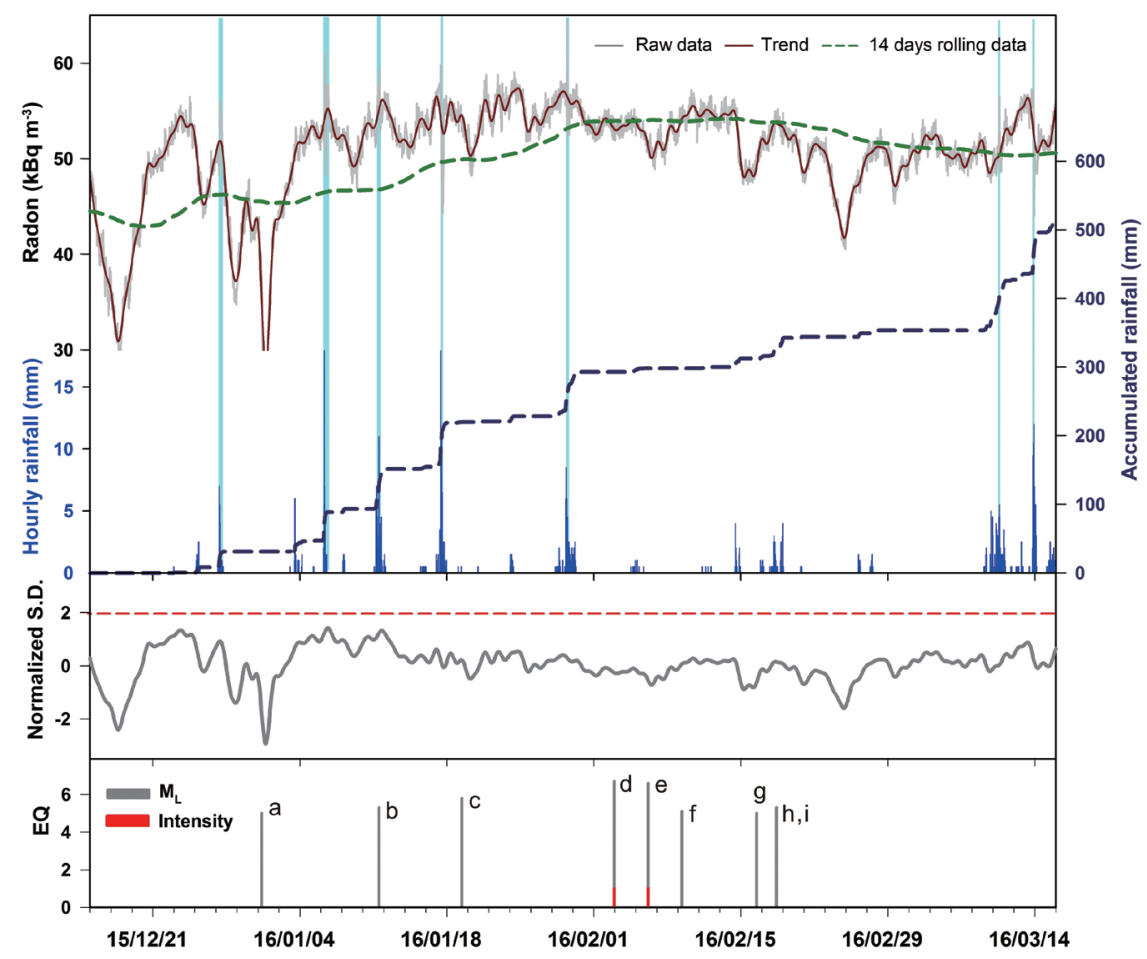

Fig. 3. The time series soil gas data, seismic events, and hourly rainfall data in a window from 15 December 2015 to 15 March 2016 at Hsinchu (HC) station. Grey line represents the raw data of radon. Brown and green line indicates the trend data and 14 days rolling average of radon. Horizontal dashed lines indicate the annual average of soil gas and the anomaly threshold value $(+2 \sigma)$. (Color online only) 


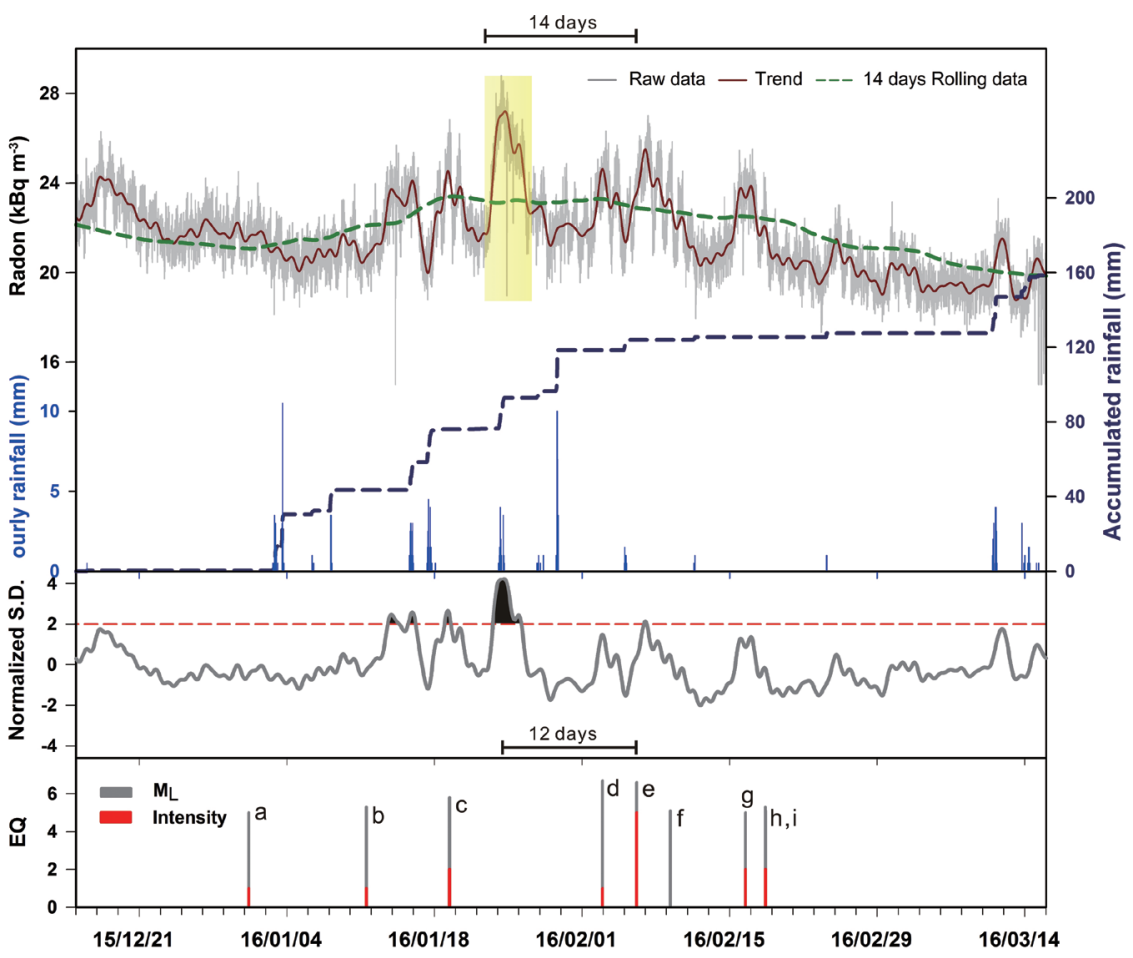

Fig. 4. The time series soil gas data, seismic events, and hourly rainfall data in a window from 15 December 2015 to 15 March 2016 at Pingtung (PT) station. Grey line represents the raw data of radon. Brown and green line indicates the trend data and 14 days rolling average of radon. Horizontal dashed lines indicate the annual average of soil gas and the anomaly threshold value $(+2 \sigma)$. The yellow shadow indicates the duration of soil radon anomalies for the Meinong earthquake. (Color online only)

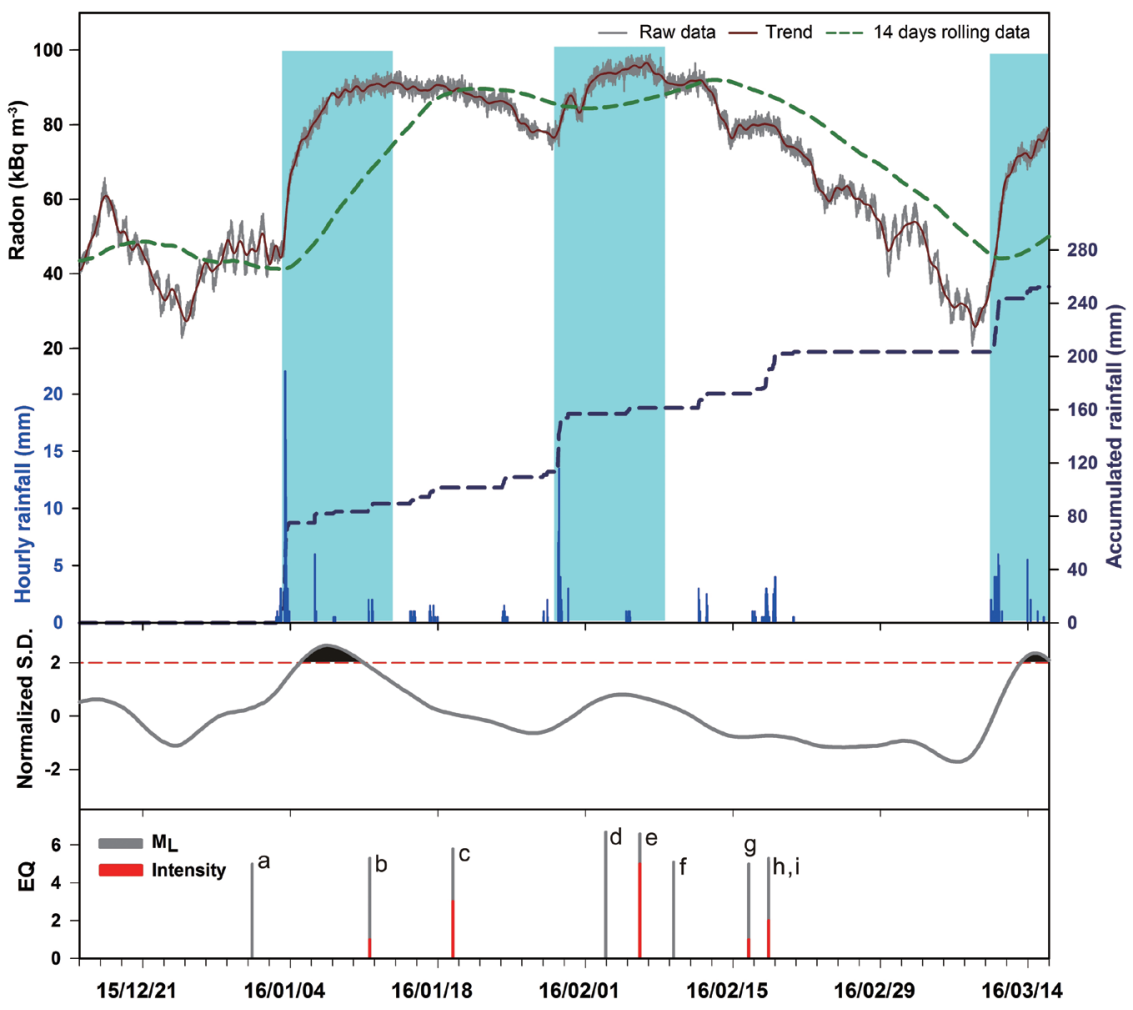

Fig. 5. The time series soil gas data, seismic events, and hourly rainfall data in a window from 15 December 2015 to 15 March 2016 at Hsinhua (HH) station. Grey line represents the raw data of radon. Brown and green line indicates the trend data and 14 days rolling average of radon. Horizontal dashed lines indicate the annual average of soil gas and the anomaly threshold value $(+2 \sigma)$. The pale blue shadows indicate radon concentrations affected by heavy rainfall in this period. (Color online only) 


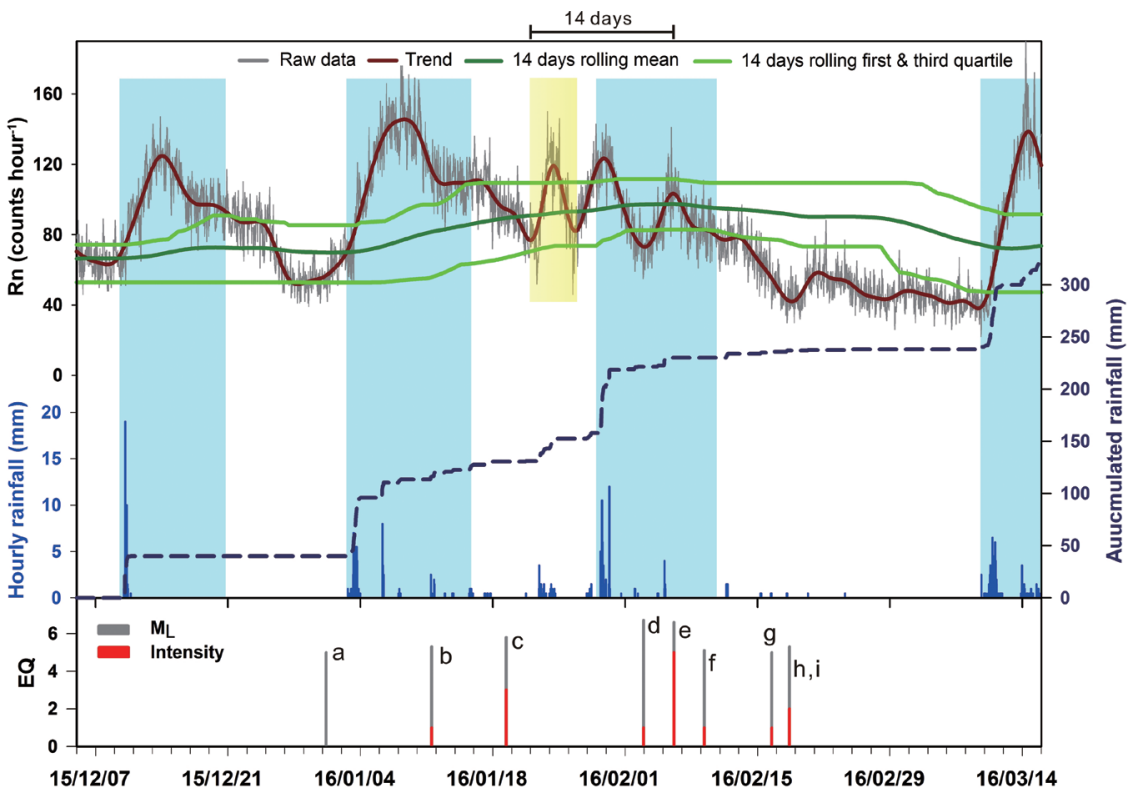

Fig. 6. The time series soil gas data, seismic events, and hourly rainfall data in a window from 15 December 2015 to 15 March 2016 at ChunglunT1 (CL-T1) station. Grey line represents the raw data of radon. Brown, green, pale green line indicates the trend data, 14 days rolling average, first and third quartile of radon, respectively. Horizontal dashed lines indicate the annual average of soil gas and the anomaly threshold value $(+2 \sigma)$. The pale blue shadows indicate radon concentrations affected by heavy rainfall in this period. The yellow shadow indicates the duration of soil radon anomalies for the Meinong earthquake. (Color online only)

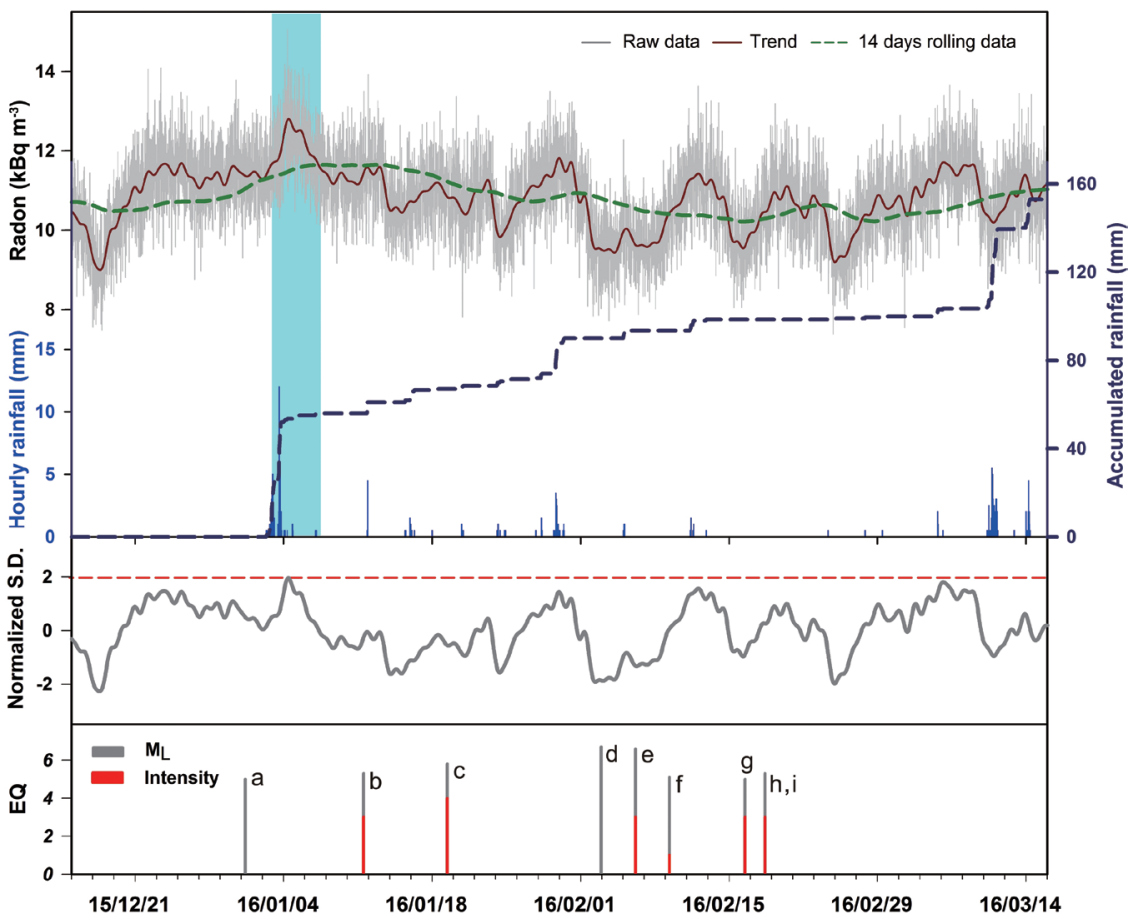

Fig. 7. The time series soil gas data, seismic events, and hourly rainfall data in a window from 15 December 2015 to 15 March 2016 at Chihshang (CS) station. Grey line represents the raw data of radon. Brown and green line indicates the trend data, 14 days rolling average of radon, respectively. Horizontal dashed lines indicate the annual average of soil gas and the anomaly threshold value $(+2 \delta)$. The pale blue shadows indicate radon concentrations affected by heavy rainfall in this period. (Color online only) 
recorded the largest peak ground acceleration of $401 \mathrm{~cm} \mathrm{~s}^{-2}$ in the East-West direction.

Radon time series at CL-T1 station from 5 December 2015 to 15 March 2016 is shown in Fig. 6. The CL-T1 monitoring station which is located at about $51 \mathrm{~km}$, distance from the epicenter of Meinong earthquake having local intensity of 5 has shown a similar kind of anomaly as for $\mathrm{HH}$ monitoring station (Fig. 5). Similar to HH station, the significant increase in radon values were also attributed to heavy rainfall (e.g., accumulated daily rainfall $>30 \mathrm{~mm}$ or hourly rainfall $>10 \mathrm{~mm}$ ) on 10 December 2015, 3 January, 29 January, and 10 March 2016, respectively (as shown for the period of precipitation effect denoted by blue bar in Fig. 6). The change in values at CL-T1 station in particular could be due to big rainfall persisting for 10 - 12 days, especially recorded as daily precipitation if it was greater than $30 \mathrm{~mm}$. After this period of high precipitation effect, the increase in radon concentrations was observed on 23 January 2016 at CL-T1 station, i.e., about 14 days before the Meniong earthquake. This result was found to be similar to the observation at PT station. Radon values at all monitoring stations in Southern zone came back to the baseline values few days after the earthquake magnitude 6.6 when aftershocks started fading away.

Moreover, CS monitoring station is located about $75 \mathrm{kms}$ from the epicenter of Meinong earthquake in Taitung county in SE Taiwan. Radon time series at CS station from 15 December 2015 to 15 March 2016 is shown in Fig. 7. This station has recorded the local intensity of almost 3 . The increasing patterns in radon started developing from 23 January 2016 with maxima recorded from 29 to 30 January 2016 about 8 days before the Meinong earthquake. Although the threshold value (crossing $+2 \sigma$ level in standard deviation) was not approached clearly but found to be very close to it. Late response of radon increase at this monitoring station is indicative of the fact that the stress distribution for this earthquake was more towards the Western side. It is also to be noticed that the higher local intensity at the location of monitoring stations was found at the Western part than the Eastern part of Taiwan (Lee et al. 2016; Wu et al. 2016). It is also associated with the larger ground acceleration recorded in the Western part during the Meinong earthquake. During the observation period, soil radon emission at CS station may also be affected by surface creeping of the Chihshan Fault, and then emission was slightly restrained (Fu et al. 2009). It could be explained that two large earthquakes with magnitude 5.3 and 5.8 , which occurred on 13 January and 19 January 2016 in Southeastern Taiwan, respectively, the significant changes in soil radon were not observed.

According to the Dobrovolsky equation by Dobrovolsky et al. (1979) and also the review of algorithms in seismogeochemistry by Etiope et al. (1997) (cited in Quattrocchi 1999), the earthquake preparation area for the Meinong earthquake was calculated to be around $687 \mathrm{~km}$.
$R=10^{0.43 M}$

where $M$ is the magnitude of the earthquake and $R$ is the radius in $\mathrm{km}$. In this case, the anomalies should be observed at all stations in the preparation area prior to the Meinong earthquake. However, monitoring stations in North and Northeastern part of Taiwan did not show precursory signals for the above mentioned earthquake magnitude 6.6 and results are not presented here deserving interest for a dedicated paper for the Northern sector of Taiwan. It may be associated with the homogeneous components of crust, which could affect the stress transfer and strain accumulation. Moreover, if we draw periphery epicentral distance circles, having radius $\leq 100 \mathrm{~km}$ for these monitoring stations, we can observe that the above mentioned earthquake occurred in the intersection of these circles (Fig. 8). Simultaneously related anomalous radon patterns, which lasted for a longer period of time at all the South monitoring stations, especially at PT and CL-T1, along with the Southeastern monitoring station are interpreted to be representative as precursory signals to the Meinong earthquake. Similarly, Fu and Lee (2017) has reported significant changes in soil radon simultaneously at four stations in southern Taiwan approximately two weeks before the 2010 Jiasian earthquake. Furthermore, the significant rate-slow-down anomalies in cGPS pre-seismic baseline variations near the epicenter of the Meinong earthquake were also demonstrated in southern Taiwan (Tsai et al. 2017). A 3D modelling work, i.e., mass flow-reactivegeomechanical transport is necessary in future.

\section{CONCLUSIONS}

Continuous monitoring of the soil gas indicates that radon concentrations show some precursory anomalies several days before major earthquakes. Significant changes in soil radon at four stations were recorded two weeks before the Meinong earthquake in Southern Taiwan. Statistical analyses of observational data were performed to identify anomalies and improve the reliability of soil radon variations under automatic detection further efforts will be made to add stations in groundwater and for other parameters being more efficient to wider areas. Furthermore, according to our working hypothesis, variations of soil radon at different stations show simultaneously precursory anomalies that can assist in expecting the approximate location of the impending major earthquake (Fig. 8) occurred effectively with a delay of two weeks as typical in the relations between faults-fractures-fluids (Frima et al. 2005) in a pore pressure increase episode at regional scale. Changes in the strain field during the build-up of stress before seismic activity can affect the gas and fluid migration due to opening or closing of fractures. Persistent heavy rain for one week may provide an intense rain in the area of the studied earthquakes. However, the precipitation effect is too shallow to be referred to 


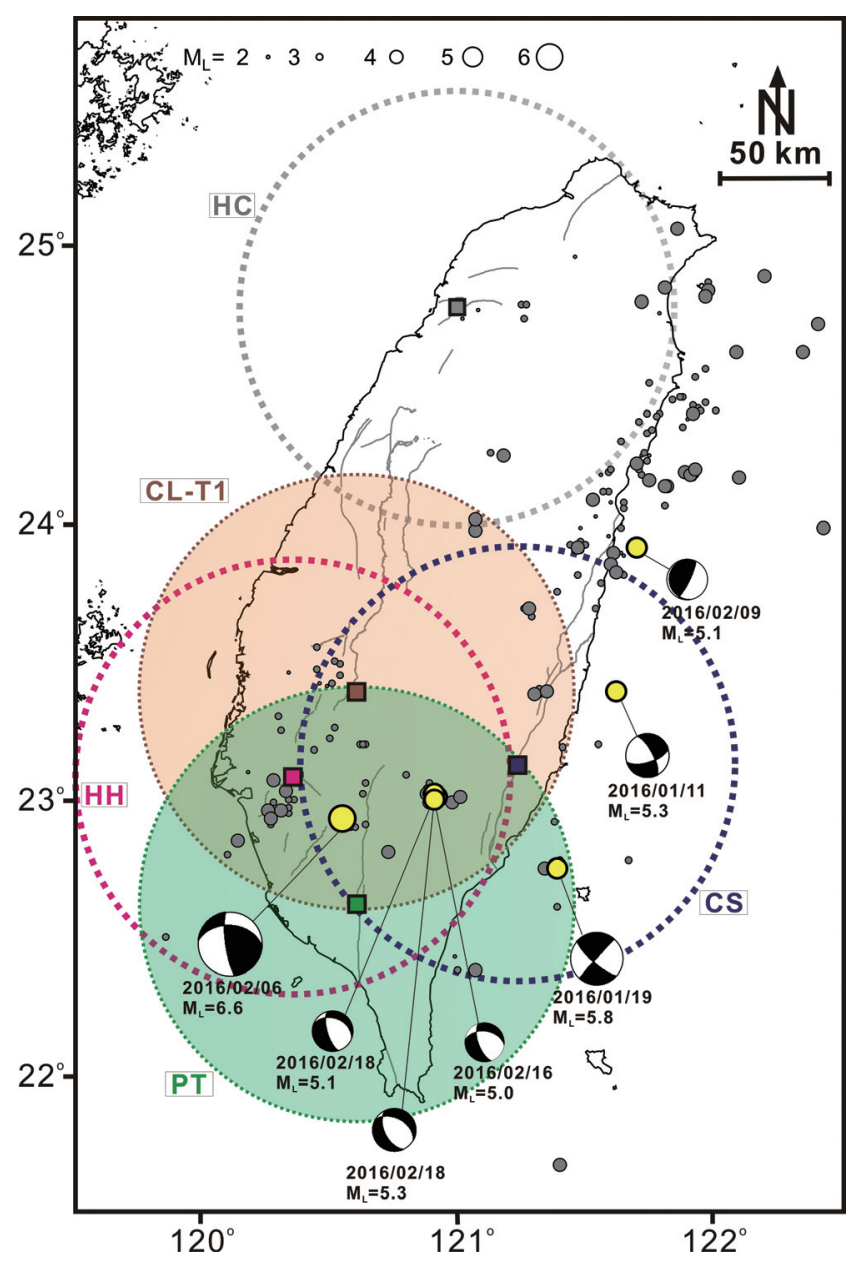

Fig. 8. The simplified tectonic map of Taiwan and the distribution of earthquake detectable zones at each soil gas station are shown by different circles and colors. The squares represent the location of the soil gas stations; HC: Hsinchu; CL-T1: Chunglun-T1; HH: Hsinhua; PT: Pingtung; CS: Chihshang. The grey circle symbols represent the distributions of earthquake during 15 December 2015 to 15 March 2016. The yellow circle symbols indicate these earthquakes are greater than magnitude 5 along with the focal mechanism (the beach ball). The grey lines indicate the active fault proposed by the Central Geological Survey of Taiwan (Lin et al. 2000). (Color online only)

the deep earthquake (Jimenez and Garcia-Fernandez 2000; Menzies et al.2016). The soil radon measurements provide a useful tool for exploring earthquake precursors in Taiwan.

Acknowledgements This research is dedicated to Prof. Tsanyao Frank Yang (TFY), who passed away on 12th March 2015. Born in 1961, he worked for many years at the Department of Geosciences, National Taiwan University (NTU), Taipei in Taiwan. His passion for research set a new standard for his students and co-workers. TFY set up the geochemical monitoring stations to understand preearthquake signals and proposed a potential model for their future use in Taiwan. We also like to dedicated this paper to Late Prof. Lindgren Lin Chyi (LLC), he worked in Depart- ment of Geology, University of Akron, Akron, U.S.A and had long-term collaboration with our group. Both TFY and LLC will be greatly missed in the Earth science community. We deeply appreciate all their contributions. We also thank Mr. K.W. Wu for help in the setting and maintenance of soil gas monitoring station. This work is financially supported by grant 105-5226904000-03-01 through the Central Geological Survey of Taiwan. The research is also supported by grants MOST104-2119-M-001-004, MOST105-2811-M-001-010 and the Taiwan Earthquake Research Center (TEC), which is funded by the Ministry of Science and Technology (MOST). The TEC contribution number for this article is 00133 . We also thankful to Dr. Fedora Quattrocchi and another anonymous reviewer for their valuable comments and suggestions, which helped us to improve the manuscript.

\section{REFERENCES}

Barnet, I., A. Kies, L. Skalský, and J. Procházka, 1997: Radon variations and earth tides in the unventilated underground spaces. Bull. Chech. Geol. Surv., 72, 105-114.

Chyi, L. L., C. Y. Chou, T. F. Yang, and C. H. Chen, 2001: Continuous radon measurements in faults and earthquake precursor pattern recognition. Western Pacific Earth Sci., 1, 43-72.

Chyi, L. L., T. J. Quick, T. F. Yang, and C. H. Chen, 2005: Soil gas radon spectra and earthquakes. Terr. Atmos. Ocean. Sci., 16, 763-774, doi: 10.3319/ TAO.2005.16.4.763(GIG). [Link]

Chyi, L. L., T. J. Quick, F. T. Yang, and C. H. Chen, 2011: The origin and detection of spike-like anomalies in soil gas radon time series. Geochem. J., 45, 431-438, doi: 10.2343/geochemj.1.0145. [Link]

Dobrovolsky, I. P., S. I. Zubkov, and V. I. Miachkin, 1979: Estimation of the size of earthquake preparation zone. Pure Appl. Geophys., 117, 1025-1044, doi: 10.1007/ BF00876083. [Link]

Einarsson, P., P. Theodorsson, A. Hjartardottir, and G. I. Guojonsson, 2008: Radon Changes Associated with the Earthquake Sequence in June 2000 in the South Iceland Seismic Zone. Pure Appl. Geophys., 165, 6374, doi: 10.1007/s00024-007-0292-6. [Link]

Etiope, G., M. Calcara, and F. Quattrocchi, 1997: Seismogeochemical algorithms for earthquake prediction: an overview. Ann Geophys., 40, 1483-1492, doi: 10.4401/ ag-3825. [Link]

Fleischer, R. L., 1981: Dislocation model for radon response to distant earthquakes. Geophys. Res. Lett., 8, 477-480, doi: 10.1029/GL008i005p00477. [Link]

Frima, C., I. Moretti, E. Brosse, F. Quattrocchi, and L. Pizzino, 2005: Can diagenetic processes influence the short term hydraulic behaviour evolution of a fault. Oil Gas Sci.Technol., 60, 213-230, doi: 10.2516/ogst:2005013. [Link] 
Fu, C. C. and L. C. Lee, 2017: Continuous monitoring of fluid and gas geochemistry for seismic study in Taiwan. AGU Books. (accepted)

Fu, C. C., T. F. Yang, V. Walia, and C. H. Chen, 2005: Reconnaissance of soil gas composition over the buried fault and fracture zone in Southern Taiwan. Geochem. J., 39, 427-439, doi: 10.2343/geochemj.39.427. [Link]

Fu, C. C., T. F. Yang, J. Du, V. Walia, Y. G. Chen, T. K. Liu, and C. H. Chen, 2008: Variations of helium and radon concentrations in soil gases from an active fault zone in Southern Taiwan. Radiat. Meas., 43, 348-352, doi: 10.1016/j.radmeas.2008.03.035. [Link]

Fu, C. C., T. F. Yang, V. Walia, T. K. Liu, S. J. Lin, C. H. Chen, and C. S. Hou, 2009: Variations of soil-gas composition around the active Chihshang Fault in a plate suture zone, Eastern Taiwan. Radiat. Meas., 44, 940944, doi: 10.1016/j.radmeas.2009.10.095. [Link]

Fu, C. C., P. K. Wang, L. C. Lee, C. H. Lin, W. Y. Chang, G. Giuliani, and D. Ouzounov, 2015: Temporal variation of gamma rays as a possible precursor of earthquake in the Longitudinal Valley of Eastern Taiwan. J. Asian Earth Sci., 114, 362-372, doi: 10.1016/j.jseaes.2015.04.035. [Link]

Fu, C. C., T. F. Yang, C. H. Chen, L. C. Lee, Y. M. Wu, T. K. Liu, V. Walia, A. Kumar, and T. H. Lai, 2017a: Spatial and temporal anomalies of soil gas in northern Taiwan and its tectonic and seismic implications. $J$. Asian Earth Sci., doi: 10.1016/j.jseaes.2017.02.032. (in press) [Link]

Fu, C. C., T. F. Yang, M. C. Tsai, L. C. Lee, T. K. Liu, V. Walia, C. H. Chen, W. Y. Chang, A. Kumar, and T. H. Lai, 2017b: Exploring the relationship between soil degassing and seismic activity by continuous radon monitoring in the Longitudinal Valley of eastern Taiwan. Chem. Geol., 469, 163-175, doi: 10.1016/j. chemgeo.2016.12.042. [Link]

Ghosh, D., A. Deb, R. Sengupta, S. Bera, and K. K. Patra, 2007: Pronounced soil radon anomaly-precursor of recent earthquakes in India. Radiat. Meas., 42, 466471, doi: 10.1016/j.radmeas.2006.12.008. [Link]

Gregorič, A., A. Zidanšek, and J. Vaupotič, 2011: Dependence of radon levels in Postojna cave on outside air temperature. Nat. Hazards Earth Syst. Sci., 11, 15231528, doi: 10.5194/nhess-11-1523-2011. [Link]

Heinicke, J., G. Martinelli, and U. Koch, 1992: Investigation of the connection between seismicity and $\mathrm{CO} 2-$ 222Rn content in spring water at the Vogtland area (Germany): First results. Activity report 1990-1992 and proceedings, Vol. 2, XXIII General Assembly of the European Seismological Commission, Geophysical Institute, Czechoslovak Academy of Sciences.

Hu, J. C., J. Angelier, J. C. Lee, H. T. Chu, and D. Byrne, 1996: Kinematics of convergence, deformation and stress distribution in the Taiwan collision area: 2-D fi- nite-element numerical modeling. Tectonophysics, $\mathbf{2 5 5}$, 243-268, doi: 10.1016/0040-1951(95)00140-9. [Link]

Huang, M. H., H. Tung, E. J. Fielding, H. H. Huang, C. Liang, C. Huang, and J. C. Hu, 2016: Multiple fault slip triggered above the $2016 \mathrm{Mw} 6.4$ MeiNong earthquake in Taiwan. Geophys. Res. Lett., 43, 7459-7467, doi: 10.1002/2016GL069351. [Link]

Igarashi, G. and H. Wakita, 1990: Groundwater radon anomalies associated with earthquakes. Tectonophysics, 180, 237-254, doi: 10.1016/0040-1951(90)90311U. [Link]

Igarashi, G., S. Saeki, N. Takahata, and Y. Sano, 1995: Ground-Water Radon Anomaly before the Kobe Earthquake in Japan. Science, 269, 60-61, doi: 10.1126/science.269.5220.60. [Link]

Inan, S., T. Akgül, C. Seyis, R. Saatçýlar, S. Baykut, S. Ergintav, and M. Bas, 2008: Geochemical monitoring in the Marmara region (NW Turkey): A search for precursors of seismic activity. J. Geophys. Res., 113, B03401, doi: 10.1029/2007JB005206. [Link]

Jaishi, H. P., S. Singh, R. P. Tiwari, and R. C. Tiwari, 2014: Temporal variation of soil radon and thoron concentrations in Mizoram (India), associated with earthquakes. Nat. Hazards, 72, 443-454, doi: 10.1007/s11069-0131020-4. [Link]

Jimenez, M. J. and M. Garcia-Fernandez, 2000: Occurrence of shallow earthquakes following periods of intense rainfall in Tenerife, Canary Islands. J. Volcanol. Geother. Res., 103, 463-468, doi: 10.1016/S03770273(00)00237-7. [Link]

Kumar, A., S. Singh, S. Mahajan, B. S. Bajwa, R. Kalia, and S. Dhar, 2009: Earthquake precursory studies in Kangra valley of North West Himalayas, India, with special emphasis on radon emission. Appl. Radiat. Isot., 67, 1904-1911, doi: 10.1016/j.apradiso.2009.05.016. [Link]

Kumar, A., V. Walia, B. R. Arora, T. F. Yang, S. J. Lin, C. C. Fu, C. H. Chen, and K. L. Wen, 2015: Identifications and removal of diurnal and semi-diurnal variations in radon time-series data of Hsinhua monitoring station in SW Taiwan using singular spectrum analysis. Nat. Hazards, 79, 317-330, doi: 10.1007/s11069-015-18441. [Link]

Kuo, T., C. Lin, G. Chang, K. Fan, W. Cheng, and C. Lewis, 2010: Estimation of aseimic crustal-strain using radon Repetitive radon precursors of the 2003 M 6.8, 2006 M 6.1, and 2008 M 5.0 earthquakes in eastern Taiwan. Nat. Hazards, 53, 219-228, doi: 10.1007/s11069-0099423-y. [Link]

Lee, S. J., T. Y. Yeh, and Y. Y. Lin, 2016: Anomalously large ground motion in the $2016 \mathrm{M}_{\mathrm{L}} 6.6$ Meinong, Taiwan, Earthquake: A synergy effect of source rupture and site amplification. Seismol. Res. Lett., 87, doi: 10.1785/0220160082. [Link] 
Lin, C. W., W. C. Chang, S. T. Lu, T. S. Shih, and W. C. Huang, 2000: An introduction to the active faults of Taiwan (2 $2^{\text {nd }}$ Ed.). Spec. Publ. Cent. Geol. Surv., 13, 1-122. (in Chinese)

Menzies, C. D., D. A. H. Teagle, S. Niedermann, S. C. Cox, D. Craw, M. Zimmer, M. J. Cooper, and J. Erzinger, 2016: The fluid budget of a continental plate boundary fault: Quantification from the Alpine Fault, New Zealand. Earth Planet. Sci. Lett., 445, 125-135, doi: 10.1016/j.epsl.2016.03.046. [Link]

Oh, Y. H. and G. Kim, 2015: A radon-thoron isotope pair as a reliable earthquake precursor. Sci.Rep., 5, 13084, doi: 10.1038/srep13084. [Link]

Pascale, F. T., P. Carbone, S. De Francesco, E. Cuoco, and D. Tedesco, 2015: Rainstorm-induced soil ${ }^{222} \mathrm{Rn}$ concentration spikes observed in Southern Italy. Environ. Earth Sci., 73, 8177-8187, doi: 10.1007/s12665014-3976-0. [Link]

Pinault, J. L. and J. C. Baubron, 1996: Signal processing of soil gas radon, atmospheric pressure, moisture, and soil temperature data: a new approach for radon concentration modelling. J. Geophys. Res., 101, 3157-3171, doi: 10.1029/95JB03121. [Link]

Quattrocchi, F., 1999: In search of evidences of deep fluid discharges and pore pressure evolution in the crust to explain the seismicity style of Umbria-Marche 199798 seismic sequence (Central Italy). Ann Geophys., 42, 609-636.

Quattrocchi, F., R. Pik, M. Angelone, M. Barbieri, M. Conti, M. Guerra, S. Lombardi, B. Marty, L. Pizzino, E. Sacchi, P. Scarlato, and G. M. Zuppi, 2000: Geochemical changes at the Bagni di Triponzo thermal spring, during the Umbria-Marche 1997-98 seismic sequence. $J$. Seismol., 4, 567-587, doi: 10.1023/A:1026590028678. [Link]

Ramola, R. C., Y. Prasad, G. Prasad, S. Kumar, and V. M. Choubey, 2008: Soil-gas radon as seismotectonic indicator in Garhwal Himalaya. Appl. Radiat. Isot., 66, 1523-1530, doi: 10.1016/j.apradiso.2008.04.006. [Link]

Sibson, R. H. 1977: Fault rocks and fault mechanisms. J. geol. Soc. Land., 133, 191-214, doi: 10.1144/ gsjgs.133.3.0191. [Link]

Steinitz, G., Z. B. Begin, and N. Gazit-Yaari, 2003: A statistically significant relation between $\mathrm{Rn}$ flux and weak earthquakes in the Dead Sea rift valley. Geology, 31, 505-508, doi: 10.1130/0091-7613. [Link]

Suppe, J., 1984: Kinematics of arc-continent collision, flipping of subduction and back-arc spreading near Taiwan. Mem. Geol. Soc. China, 6, 21-33.

Tarakci, M., C. Harmansah, M. M. Sac, and M. Ichedef, 2014: Investigation of the relationships between seismic activities and radon level in Western Turkey. Appl. Radiat. Isot., 83, 12-17, doi: 10.1016/j.aprad- iso.2013.10.008. [Link]

Tsai, M.-C., T.-C. Shin, and K.-W. Kuo, 2017: Pre-seismic strain anomalies and coseismic deformation of Meinong earthquake from continuous GPS. Terr. Atmos. Ocean. Sci., 28, 763-785, doi: 10.3319/TAO.2017.04.19.01. [Link]

Virk, H. S. and B. Singh, 1994: Radon recording of Uttarkashi earthquake. Geophys. Res. Lett., 21, 737-740, doi: 10.1029/94GL00310. [Link]

Virk, H. S., V. Walia, and N. Kumar, 2001: Helium/radon precursory anomalies of Chamoli earthquake, Garhwal Himalaya, India. J. Geodyn., 31, 201-210, doi: 10.1016/S0264-3707(00)00022-3. [Link]

Wakita, H., Y. Nakamura, K. Notsu, M. Noguchi, and T. Asada, 1980: Radon anomaly: A possible precursor of the 1978 Izu-Oshima-Kinkai earthquake. Science, 207, 882, doi: 10.1126/science.207.4433.882. [Link]

Walia, V., H. S. Virk, and B. S. Bajwa, 2006: Radon precursory signals for some earthquakes of magnitude $>5 \mathrm{oc}-$ curred in N-W Himalaya. Pure Applied Geophys., 163, 711-721, doi: 10.1007/s00024-006-0044-z. [Link]

Walia, V., T. F. Yang, S. J. Lin, W. L. Hong, C. C. Fu, K. L. Wen, and C. H. Chen, 2009a: Geochemical variation of soil-gas composition for fault and earthquake precursory studies along Hsincheng fault in NW Taiwan. Appl. Radiat.Isot., 67, 1855-1863, doi: 10.1016/j. apradiso.2009.07.004. [Link]

Walia, V., T. F. Yang, S. J. Lin, W. L. Hong, C. C. Fu, K. L. Wen, and C. H. Chen, 2009b: Continuous temporal soil.gas composition variations for earthquake precursory studies along Hsincheng and Hsinhua faults in Taiwan. Radiat. Meas., 44, 934-939, doi: 10.1016/j. radmeas.2009.10.010. [Link]

Walia, V., T. F. Yang, S. J. Lin, A. Kumar, C. C. Fu, J. M. Chiu, H. H. Chang, K. L. Wen, and C. H. Chen, 2013: Temporal variation of soil gas compositions for earthquake surveillance in Taiwan. Radiat. Meas., 50, 154159, doi: 10.1016/j.radmeas.2012.11.007. [Link]

Wu, Y. M., J. K. Chung, T. C. Shin, N. C. Hsiao, Y. B. Tsai, W.H. K. Lee, and T.L. Teng, 1999: Development of an integrated earthquake early warning system in Taiwancase for Hualien earthquakes. Terr. Atmos. Ocean.Sci., 10, 719-736, doi: 10.3319/TAO.1999.10.4.719(T). [Link]

Wu, Y. M., W. T. Liang, H. Mittal, W. A. Chao, C. H. Lin, B. S. Huang, and C. M. Lin, 2016: Performance of a Low-Cost Earthquake Early Warning System (P-Alert) during the 2016 ML 6.4 Meinong (Taiwan) Earthquake.Seismo.Res. Let., 87, doi: 10.1785/0220160058. [Link]

Yang, T. F., V. Walia, L. L. Chyi, C. C. Fu, C. H. Chen, T. K. Liu, S. R. Song, R. Y. Lee, and M. Lee, 2005: Variations of soil radon and thoron concentrations in a fault zone and prospective earthquakes in SW 
Taiwan. Radiat. Meas., 40, 496-502, doi: 10.1016/j. radmeas.2005.05.017. [Link]

Yang, T. F., C. C. Fu, V. Walia, C. H. Chen, L. L. Chyi, T. K. Liu, S. R. Song, M. Lee, C. W. Lin, and C. C. Lin, 2006: Seismo-geochemical variations in SW Taiwan: Multiparameter automatic gas monitoring results. Pure Appl. Geophys., 163, 693-709, doi: 10.1007/s00024006-0040-3. [Link]

Yang, T. F., T. K. Liu, and M. C. T. Kuo, 2011: Observation and research on active faults by geochemical method
(II). Cent. Geol. Survey Open-File Report, No. 100-08, $378 \mathrm{pp}$.

Yu, S. B., H. Y. Chen, and L. C. Kuo, 1997: Velocity field of GPS stations in the Taiwan area. Tectonophysics, 274, 41-59, doi: 10.1016/S0040-1951(96)00297-1. [Link]

Zmazek, B., M. Zivcic, L. Todorovski, S. Dzeroski, J. Vaupotic, and I. Kobal, 2005: Radon in soil gas: How to identify anomalies caused by earthquakes. Appl. Geochem., 20, 1106-1119, doi: 10.1016/j.apgeochem.2005.01.014. [Link] 